\title{
Níveis de envolvimento de uma criança com Síndrome de Down em contextos de inclusão e Educação Especial
}

\author{
Letícia Monteiro Esteves* \\ Eduardo Chaves Cruz ** \\ Rosangela Bertelli***
}

\begin{abstract}
Resumo
As crianças com necessidades educativas especiais (NEE) estão, sempre que possível, inseridas em turmas do ensino regular. A inclusão traz uma série de benefícios tanto para as crianças regulares quanto para aquelas com NEE. O presente estudo avaliou a qualidade do envolvimento de uma criança com síndrome de Down inserida numa turma de primeiro ano primário do ensino regular, em dois contextos de ensino aprendizagem: contexto de inclusão e contexto de educação especial. O estudo avaliou também o empenhamento da professora relativamente à criança com NEE, em contexto de inclusão e em contexto de educação especial. Os resultados obtidos evidenciaram que os níveis de envolvimento da criança nas atividades de sala de aula eram mais satisfatórios no contexto de educação especial. Diretamente proporcional ao envolvimento da criança era o empenhamento da professora, que atingiu níveis mais baixos de empenhamento nas atividades de sala de aula no contexto de inclusão.
\end{abstract}

Palavras-chave: Inclusão; Níveis de envolvimento; Níveis de empenhamento.

* Técnica de Educação Especial, EB2,3 D. Francisco Manuel de Melo, Amadora, Portugal.

** Professor Doutor, Universidade de Trás-os-Montes e Alto Douro, Vila Real, Portugal.

*** Professora Doutora, Universidade de Trás-os-Montes e Alto Douro, Vila Real, Portugal.

Revista Educação Especial | v. 26 | n. 45, | p. 31-44| jan./abr. 2013

Santa Maria

Disponível em: <http://www.ufsm.br/revistaeducacaoespecial> 


\title{
Levels of involvement of a child with Down's syndrome in educational contexts of inclusion and Special Education
}

\begin{abstract}
Children with special educational needs (SEN) are, whenever possible, inserted into regular school classrooms. Inclusion brings a series of benefits for both children with and without special needs. The present study evaluated the quality of the involvement of a child with Down's syndrome included in a regular group of first year primary school in two teaching learning contexts: inclusive education context and special education context. The study also evaluated the levels of teachers engagement toward the child with SEN in the contexts of inclusive and special education. Results showed that the child's involvement levels during classroom's activities were more satisfactory in the context of special education. Teachers' levels of engagement were lower during classroom's activities in the context of inclusion and proportional to the child's levels of involvement.
\end{abstract}

Keywords: Inclusive education context; Levels of involvement; Levels of engagement.

Em Portugal, os contextos de educação através da inclusão foram ganhando importância ao longo das últimas décadas e passou-se a ter expectativas positivas em relação aos alunos com necessidades educativas especiais (NEE), por exemplo, em relação aos alunos com Trissomia 21 ou síndrome de Down. "As escolas regulares, seguindo uma orientação inclusiva, constituem os meios mais eficazes para combater as atitudes discriminatórias, criando comunidades abertas e solidárias, construindo uma sociedade inclusiva e atingindo a educação para todos" (CORREIA, 1999, p. 38) e "O envolvimento em programas de educação inclusiva, bem estruturados e com os recursos adequados, promove nos professores de ensino regular atitudes mais positivas face aos alunos com dificuldades de aprendizagem" (CORREIA, 2003, p. 77). Assim, crianças com NEE começaram a participar mais ativamente no desenvolvimento da sociedade, pois puderam juntar-se às crianças nas escolas e classes regulares, obtendo maior qualidade de instrução e maior socialização. Contudo, há já alguns anos que se tem vindo a defender e implementar um conceito de inclusão em que, para além de estar integrada numa turma regular, a criança com NEE deveria estar incluída nas mesmas atividades que as crianças regulares. No entanto, "... poucos se têm debruçado sobre a melhoria da qualidade da resposta a crianças com NEE integradas em escolas regulares" (DEPARTAMENTO DE EDUCAÇÃO BÁSICA, 1998, p. 4). 
Segundo o Departamento de Educação Básica (1998, p. 90-91), consideram-se os seguintes indicadores de envolvimento da criança em sala de aula:

- Concentração: nada parece distrair a criança;

- Energia: a criança investe todo o seu esforço na atividade;

- Complexidade e criatividade: demonstra as suas maiores competências, a criatividade existe quando a criança dá um toque individual ao que faz;

- Expressão facial e postura: os indicadores não verbais são de extrema importância para apreciar o envolvimento da criança;

- Persistência: duração da concentração na atividade que está a ser realizada;

- Precisão: estão atentas aos pormenores;

- Tempo de reação: reagem com rapidez a estímulos;

- Linguagem: comentários que fazem sobre a atividade;

- Satisfação: satisfação perante os resultados alcançados.

A criança, no entanto, aprende com o adulto. O comportamento do adulto modela o comportamento da criança, que, por sua vez, modela o comportamento do adulto. A partir dessa constatação, Laevers (DEPARTAMENTO DE EDUCAÇÃO BÁSICA, 1998) identificou três categorias de comportamento do professor:

- Sensibilidade: atenção prestada pelo adulto, empatia, sinceridade e autenticidade;

- Estimulação: introduzir ou propor uma atividade, facultar informação, intervir no desenrolar da atividade para estimular;

- Autonomia: grau de liberdade que o adulto dá à criança para experimentar as suas ideias.

A partir das categorias acima, desenvolveu-se uma grelha de observação que permite identificar o estilo de intervenção do professor no processo de aprendizagem, a chamada Escala de Empenhamento do Adulto. Segundo Oliveira-Formosinho (2009, p. 16) "...Essas caraterísticas influenciam a competência do adulto para motivar, alargar, promover e envolver a criança no processo de aprendizagem". 
Consideram-se, segundo o Departamento de Educação Básica (1998, p. 107), os seguintes indicadores de empenhamento do adulto em sala de aula:

- Sensibilidade: adota um tom de voz encorajador, faz gestos de encorajamento e estabelece contato visual, é carinhoso e afetuoso, respeita e valoriza a criança, encoraja e elogia, mostra empatia com as necessidades e preocupações da criança, ouve a criança e responde-Ihe, fomenta a confiança da criança;

- Estimulação: tem energia e vida, é adequada, corresponde às capacidades e interesses da criança, motiva a criança, é diversificada e clara, estimula o diálogo, a atividade ou o pensamento, partilha e valoriza as atividades da criança, não verbal;

- Autonomia: permite à criança escolher e apoia a sua escolha, dá oportunidades à criança para experimentar, encoraja a criança a dar as suas idéias e a assumir responsabilidades, respeita as opiniões da criança sobre a qualidade do trabalho realizado, encoraja a criança a resolver conflitos.

Oliveira-Formosinho (2009) verificou que o envolvimento da criança na tarefa aumentava quando os educadores se empenhavam na organização e estruturação das contingências de aprendizagem.

Será que os níveis de envolvimento que uma criança com síndrome de Down consegue atingir em ambos contextos (de educação inclusiva e de educação especial) seriam equivalentes? Assim, para responder à questão, investigou-se a qualidade das respostas operantes emitidas por uma menina com NEE, inserida numa turma regular (contexto inclusivo) e recebendo apoio especial fora da sala de aula (contexto de educação especial).

Relativamente à síndrome de Down, existem registros (desenhos e esculturas) da presença de crianças com essas características que datam da época dos Olmecas (1300 - $600 \mathrm{aC}$ ). O grau de prejuízo do desenvolvimento motor e cognitivo variam de indivíduo para indivíduo, sendo que o aspecto cognitivo é geralmente o mais afetado (NIELSEN, 1999), produzindo alguma lentidão no processamento geral de informação (codificação, consolidação, armazenamento, recuperação e memória de trabalho) e na emissão de respostas operantes. 
Os objetivos específicos foram:

- descrever como a criança com NEE se comporta em sala de aula de educação regular (variável independente) e em sala de aula de educação especial (variável independente);

- descrever o seu nível de envolvimento (variável dependente) em cada um desses contextos de ensino aprendizagem;

- descrever o nível de empenhamento (variável dependente) dos adultos responsáveis em cada um desses contextos;

- contrastar o nível de envolvimento da criança com o nível de empenhamento do adulto.

De acordo com o Departamento de Educação Básica (1998, p. 92) existem cinco níveis de envolvimento:

- Nível 1 (inatividade): neste nível, a atividade é simples, estereotipada, repetitiva, passiva e a criança parece estar ausente e não demonstra energia;

- Nível 2 (atividade interrompida frequentemente): neste nível a criança está a executar uma determinada atividade, mas metade do período de observação inclui momentos de ausência de atividade, durante os quais a criança não está concentrada e está só a olhar para o ar;

- Nível 3 (atividade mais ou menos contínua): a criança encontrase ocupada numa atividade, faz alguns progressos, mas sem muito interesse nem especial concentração e distrai-se facilmente.

- Nível 4 (atividade com momentos de grande intensidade): a atividade da criança passa por momentos de grande intensidade, mesmo que haja interrupções, o nível da atividade é retomada.

- Nível 5 (atividade contínua e intensa): a criança demonstra, através da atividade continuada e intensa, que está a desenvolver, que atingiu o mais elevado grau de envolvimento. Podem ou não estar presentes todos os sinais de envolvimento, mas devem estar presentes a concentração, criatividade, energia e persistência.

Em relação ao empenhamento do adulto, o Departamento de Educação Básica (1998, p. 105) considera também cinco níveis de empenhamento:

- Nível 1 - atitudes de falta total de empenhamento;

Revista Educação Especial | v. 26 | n. 45, | p. 31-44| jan./abr. 2013

Santa Maria

Disponível em: <http://www.ufsm.br/revistaeducacaoespecial> 
- Nível 2 - atitudes predominantes de falta de empenhamento com traços de empenhamento;

- Nível 3 - atitudes nem de empenhamento nem de falta de empenhamento;

- Nível 4 - atitudes predominantes de empenhamento com traços de não empenhamento;

- Nível 5 - atitudes de total empenhamento.

Os problemas de pesquisa que nortearam esta investigação foram os seguintes:

- Seriam os contextos de educação especial mais favorecedores de um maior nível de envolvimento de uma criança com síndrome de Down do que os contextos inclusivos?

- Seriam mais elevados os níveis de empenhamento do adulto em contexto de educação especial do que em contexto inclusivo?

- Será que o nível de empenhamento do adulto exerce influência sobre o nível de envolvimento da criança?

\section{Método}

\section{Participantes}

Participaram do presente estudo uma criança portadora de síndrome de Down (diagnóstico feito logo após o nascimento) e duas professoras do primeiro ano do primeiro ciclo do ensino primário de uma escola pública. A criança, a partir de agora denominada Maria, com oito anos de idade cronológica e 36 meses de idade mental em todas as áreas do desenvolvimento, segundo relatório médico oficial, estava inserida em uma turma regular do primeiro ano primário. Ambas as professoras, do ensino regular e do ensino especial, eram experientes, tendo ambas mais de uma década de serviço no ensino primário. A turma do contexto inclusivo, onde a Maria estava integrada, era composta por outras 22 crianças entre os seis e os sete anos de idade. Em contexto de educação especial, a Maria encontrava-se sozinha com a sua professora de educação especial.

\section{Materiais}

Para fins de observação e registro dos comportamentos operantes de interesse, utilizou-se um conjunto de grelhas validadas pelo Departamento de Educação Básica (1998): 
- Escala de nível de envolvimento da criança;

- Escala de observação de empenhamento do adulto.

\section{Procedimento}

Foram feitas 10 horas de observação direta em contexto de inclusão e em contexto de educação especial. Consentimentos informados foram fornecidos pelos pais da Maria, pelas professoras (ensino regular e ensino especial) e pela escola pública onde as observações foram feitas.

As escalas de envolvimento da criança e de empenhamento do adulto foram utilizadas para recolher as seguintes informações:

- tipo de atividade proposta;

- envolvimento evidenciado pela criança em cada fase da atividade;

- empenhamento evidenciado pelo adulto na realização da atividade da criança.

A coleta de informações foi executada através da observação direta, de tipo naturalista não participante, em contexto inclusivo e em contexto de educação especial. Através da escala de envolvimento da criança, observouse e registrou-se o nível (entre 1 e 5 ) de envolvimento da Maria nas atividades em andamento. Em paralelo, observou-se e registrou-se os comportamentos das professores, através da escala (entre 1 e 5) de empenhamento do adulto. Sendo ambas escalas que recorrem ao uso de cruzes ou siglas, eram de preenchimento extremamente simples.

\section{Resultados}

Seriam os contextos de educação especial mais favorecedores de um maior nível de envolvimento de uma criança com síndrome de Down do que os contextos inclusivos?

Seguindo os indicadores anteriormente referidos, avaliou-se o nível de envolvimento da Maria durante a realização das atividades: concentração, energia, nível de complexidade no uso das suas competências e criatividade, expressão facial e postura, persistência, atenção aos pormenores, tempo de reação, linguagem utilizada durante as atividades e satisfação demonstrada diante dos resultados alcançados. O nível de envolvimento foi classificado em uma escala entre 1 e 5 . A média de envolvimento atingida nas aulas em contexto inclusivo foi claramente inferior à média atingida no contexto da 
educação especial: 2.14 contra 3.47. Por vezes, dentro da mesma atividade, e nas mais demoradas, a criança era avaliada em dois níveis diferentes, consequentemente, a média nessas atividades nem sempre era classificada em números inteiros.

Nas aulas de contexto de educação especial, a Maria apresentava níveis de envolvimento que variavam entre 2 e 5 . Assim, em $57.89 \%$ das atividades, a Maria alcançava níveis de envolvimento entre 2 e 3 , interpolando assim atividades interrompidas frequentemente e atividades mais ou menos contínuas. Em $26.32 \%$ das atividades observadas, o envolvimento da Maria atingiu nível 4. Em outras palavras, passou por momentos de grande intensidade. Além disso, a Maria realizou atividades contínuas e intensas em $15.79 \%$ das atividades presenciadas.

Em contexto inclusivo, os níveis de envolvimento observados foram desde 1 até 4 , sendo que em diversas atividades a Maria apresentou diversos níveis de envolvimento na mesma atividade. O nível 1 foi atingido em $5.56 \%$ dos casos, o nível 2 em $50 \%$ dos casos e o nível 3 em $16.67 \%$ das atividades. Em 5.56\% das atividades observadas, a Maria apresentou um envolvimento intermitente entre e os níveis 1 e 2 e os níveis 3 e 4 . Nos $16.67 \%$ restantes, a Maria esteve entre os níveis 2 e 3 . Em síntese, a Maria esteve maioritariamente no nível 2 , que é o nível equivalente às atividades interrompidas frequentemente.

A Figura 1 ilustra que a Maria apresentava níveis de envolvimento muito reduzidos em contexto de inclusão, jamais demonstrando envolvimento de níveis 4 e 5 . Em contexto de educação especial, verifica-se que os níveis de envolvimento da Maria são consideravelmente mais elevados.

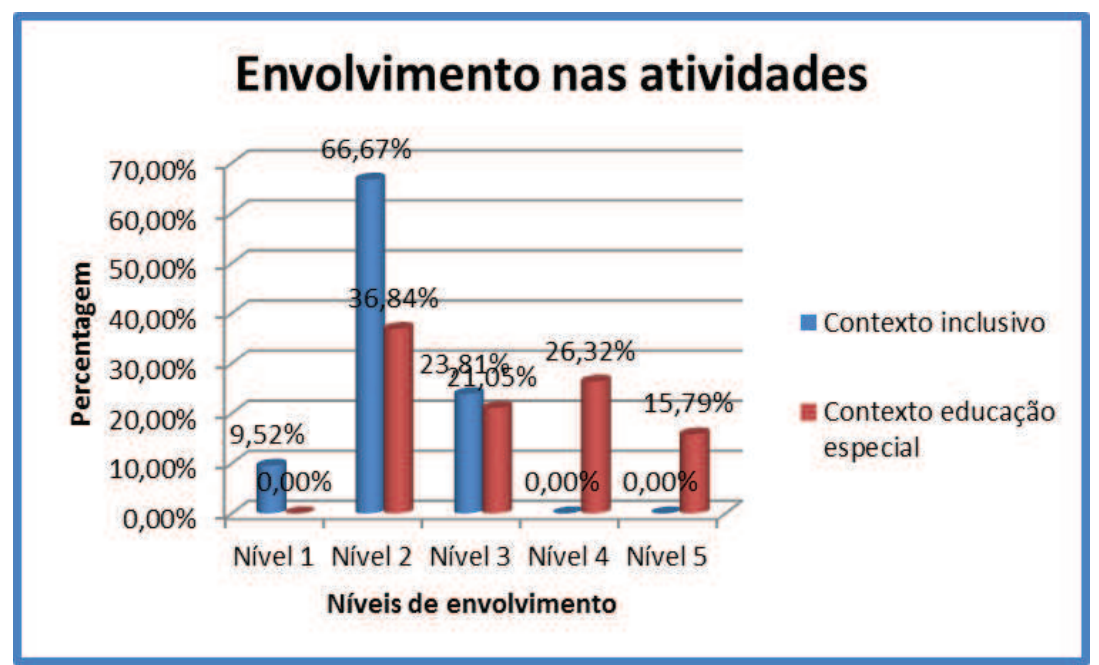

Figura 1. Níveis de envolvimento da Maria 
Seriam mais elevados os níveis de empenhamento do adulto em contexto de educação especial do que em contexto inclusivo?

Conforme já referido, os indicadores de empenhamento são: sensibilidade, estimulação e autonomia. Assim, verificou-se a atenção prestada pelo adulto às atividades da criança, a sua empatia e sinceridade, os elogios e encorajamentos oferecidos. Observou-se ainda a forma como as atividades eram introduzidas, as informações facultadas e a intervenção do adulto no desenrolar da atividade, o grau de liberdade que o adulto fornecia à criança para experimentar, escolher as atividades e exprimir as suas ideias. Após a análise de cada elemento, atribuiu-se um nível entre 1 e 5 para classificar o empenhamento geral do adulto.

Nas aulas em contexto inclusivo, a professora obteve uma média de 2.19 de empenhamento, muito semelhante ao envolvimento da Maria, que se situava em 2.14. Assim, $66.67 \%$ das atividades observadas foram registras com um empenhamento do adulto de nível 2 (atitudes predominantes de falta de empenhamento com traços de empenhamento), $19.05 \%$ eram de nível 3 (atitudes nem de empenhamento nem de falta de empenhamento), $9.52 \%$ foram atribuídas ao nível 1 (atitudes de falta total de empenhamento), enquanto $4.76 \%$ foram de nível 4 (atitudes predominantes de empenhamento com traços de não empenhamento). Nunca o empenhamento da professora esteve dentro dos registros de nível 5 (atitudes de total empenhamento).

Nas aulas em contexto de educação especial, a média de empenhamento da professora foi superior, 3.37 de nível de empenhamento, muito similar à média de envolvimento da criança no mesmo contexto, 3.47. A mesma percentagem de atividades observadas foi classificada em níveis 2 e 5: $15.79 \%$. O empenhamento da professora foi classificada de nível 3 em $26.32 \%$ das atividades, enquanto que $42.11 \%$ das atividades foram classificadas de nível 4 . O nível 1 de empenhamento nunca foi presenciado.

A Figura 2 ilustra que o empenhamento da professora em contexto de educação especial mostra-se superior ao empenhamento da professora em contexto de inclusão.

Será que o nível de empenhamento do adulto exerce influência sobre o nível de envolvimento da criança?

Relacionando os dados através da correlação de Pearson, as Tabelas 1 e 2 evidenciam uma correlação positiva entre o envolvimento da Maria na tarefa e o empenhamento da professora na tarefa em contexto de educação especial. A correlação é significativa ao nível de significância .05. 
Relacionando ainda os dados através da correlação de Pearson, as Tabelas 3 e 4 evidenciam a existência de uma correlação positiva entre o envolvimento da Maria na tarefa e o empenhamento da professora na tarefa em contexto de inclusão. A correlação entre as duas variáveis situa-se ao nível de significância .01.

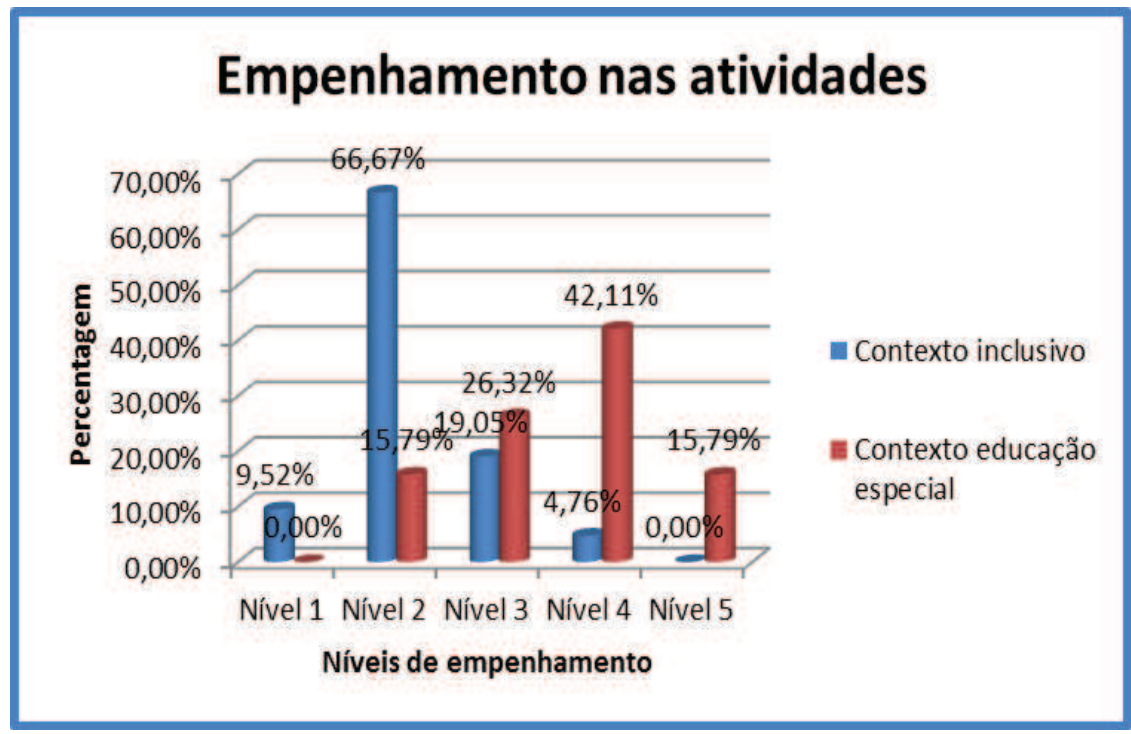

Figura 2. Níveis de empenhamento da professora

Tabela 1. Relação empenhamento/envolvimento em contexto de educação especial

Empenhamento * Envolvimento Tabulação cruzada

\begin{tabular}{|r|c|c|c|c|c|}
\hline \multicolumn{7}{|c|}{ Contagem } \\
\cline { 2 - 6 } & 00002 & 00003 & 00004 & 00005 & \\
\hline 00002 & 2 & 0 & 0 & 1 & 3 \\
\cline { 2 - 6 } 00003 & 4 & 1 & 0 & 0 & 5 \\
\cline { 2 - 6 } Empenhamento 00004 & 1 & 3 & 4 & 0 & 8 \\
\cline { 2 - 6 } 00005 & 0 & 0 & 1 & 2 & 3 \\
\cline { 2 - 6 } Total & 7 & 4 & 5 & 3 & 19 \\
\hline
\end{tabular}


Tabela 2. Correlação empenhamento/envolvimento em contexto de educação especial

\section{Correlações}

\begin{tabular}{|rr|c|c|}
\hline & & Envolvimento & Empenhamento \\
\hline \multirow{2}{*}{ Envolvimento } & Correlação de Pearson & 1 & $.544^{*}$ \\
& Sig. (2extremidades) & & .016 \\
$\mathrm{~N}$ & 19 & 19 \\
Empenhamento & Correlação de Pearson & $.544^{*}$ & 1 \\
& Sig. (2extremidades) & .016 & 19 \\
$\mathrm{~N}$ & 19 & \\
& &
\end{tabular}

* A correlação é significativa ao nível de significância .05 (duas extremidades).

Tabela 3. Relação empenhamento/envolvimento em contexto de inclusão

Empenhamento * Envolvimento Tabulação cruzada

Contagem

\begin{tabular}{|c|c|c|c|c|c|}
\hline & \multicolumn{3}{|c|}{ Envolvimento } & \multirow[b]{2}{*}{ Total } \\
\hline & & 00001 & 00002 & 00003 & \\
\hline \multirow{5}{*}{ Empenhamento } & 00001 & 1 & 1 & 0 & 2 \\
\hline & 00002 & 1 & 11 & 2 & 14 \\
\hline & 00003 & 0 & 2 & 2 & 4 \\
\hline & 00004 & 0 & 0 & 1 & 1 \\
\hline & & 2 & 14 & 5 & 21 \\
\hline
\end{tabular}

Tabela 4. Correlação empenhamento/envolvimento em contexto de inclusão

\section{Correlações}

\begin{tabular}{|rr|c|c|}
\hline & & Envolvimento & Empenhamento \\
\hline \multirow{2}{*}{ Envolvimento } & Correlação de Pearson & 1 & $.568^{* *}$ \\
& Sig. (2extremidades) & & .007 \\
$\mathrm{~N}$ & 21 & 21 \\
Empenhamento & Correlação de Pearson & $.568^{* *}$ & 1 \\
& Sig. (2extremidades) & .007 & 21 \\
$\mathrm{~N}$ & 21 & \\
& & \multicolumn{2}{|}{} \\
\hline
\end{tabular}

** A correlação é significativa ao nível de significância .01 (duas extremidades).

Os dados evidenciam que, quer em um contexto de educação especial quer em contexto inclusivo, o envolvimento da criança e o empenhamento do adulto estão intimamente relacionados e, provavelmente, influenciam-se mutuamente. 


\section{Discussão}

Os resultados obtidos evidenciaram que a Maria, uma criança portadora de Síndrome de Down e, portanto, uma criança com NEE, integrada em uma sala de aula regular, provavelmente, extraía algum benefício em termos de vários aspectos do seu desenvolvimento global, no entanto, em termos do envolvimento necessário à aprendizagem de conteúdo acadêmico, o contexto de inclusão não pareceu favorecer a evolução da Maria. Certamente a inclusão favorecerá as crianças regulares, no sentido em que permitirá que desenvolvam habilidades para lidar com a diversidade e tolerância com as diferenças. As crianças com NEE constituem um grupo extraordinariamente diverso, quando comparado à população em geral, e relativamente poucas generalizações aplicam-se a todas as crianças com NEE. As suas excepcionalidades podem envolver habilidades sensoriais, físicas, cognitivas, emocionais ou de comunicação ou ainda qualquer combinação dessas habilidades. Além disso, as excepcionalidades podem variar enormemente em termos de causa, grau e efeitos sobre o progresso educacional. Esses efeitos podem variar imensamente dependendo da idade, do sexo e das circunstâncias de vida das crianças. A integração permite que as crianças regulares percebam e encarem com naturalidade a presença de uma proporção natural de estudantes com incapacidades.

Em termos da aquisição de habilidades acadêmicas, parece que as atividades em contexto de inclusão não sejam apropriadas ao envolvimento da criança com NEE. Conforme mostram os resultados obtidos, talvez a falta de envolvimento da criança não esteja ligada ao contexto inclusivo, mas sim à falta de empenhamento da professora em contexto inclusivo relativamente à criança com NEE. Seja qual for a razão, as contingências operantes existentes na sala de aula inclusiva parecem não corresponder às necessidade educativas da criança com NEE.

É importante considerar que, para fins educacionais, a criança com NEE é aquela criança que necessita de educação especial e de outros serviços relacionados, para que possa alcançar o seu total potencial. Essa criança necessita de educação especial, porque ela é, de alguma maneira, marcadamente diferente da maioria das outras crianças. A criança com NEE pode ter um retardo mental, incapacidades de aprendizagem, desordens emocionais ou comportamentais, incapacidades físicas, desordens de comunicação, autismo, dano cerebral, prejuízo auditivo, visual ou ainda talentos especiais.

Os professores de educação especial devem focar as habilidades das crianças com NEE e não, pura e simplesmente, acomodar-se às suas deficiências. Descobrir e capitalizar as habilidades dessas crianças não 
parece ser tarefa fácil em uma sala de aula regular e exige métodos e técnicas de ensino altamente especializadas (HALLAHAN; KAUFFMAN, 1994).

A Maria mostrava mais interesse e entusiasmo com as atividades realizadas em um contexto de educação especial, onde conseguia manter de forma mais sustentada a sua capacidade concentração. A professora no contexto de educação especial empenhava-se mais no apoio ao desenvolvimento das atividades acadêmicas. A ausência das outras 22 crianças permitia que a Maria e a professora estivessem mais concentradas e envolvidas nas atividades e tarefas de aprendizagem propostas. É possível que a Maria, durante as aulas em contexto de ensino regular, estivesse incluída na turma, porém permanecesse excluída do processo de ensino aprendizagem, no sentido de que a Maria não era devidamente acompanhada.

\section{Referências}

CORREIA, L. Alunos com necessidades educativas especiais nas classes regulares. Porto: Porto, 1999.

CORREIA, L. Inclusão e necessidades educativas especiais: um guia para educadores e professores. Porto: Porto, 2003.

HALLAHAN, D. P.; KAUFFMAN, J. M. Exceptional children: introduction to special education. 6th ed. Boston: Allyn and Bacon, 1994.

NIELSEN, L. B. Necessidades educativas especiais na sala de aula. Porto: Porto, 1999.

OLIVEIRA-FORMOSINHO, J. Desenvolvendo a qualidade em parcerias. Lisboa: Direção Geral de Inovação e Desenvolvimento Curricular, 2009.

PORTUGAL. Departamento de Educação Básica. Desenvolvendo a qualidade em parcerias. Lisboa: Direção Geral de Inovação e de Desenvolvimento Curricular, 1998.

\section{Correspondência}

Eduardo Chaves Cruz - Rua Dr Manuel Cardona, apartado 1013, CEP 5001-558, Vila Real - Portugal

E-mail: echaves@utad.pt - laetitia-07@hotmail.com - bertelli@utad.pt

Recebido em 08 de junho de 2012

Aprovado em 21 de agosto de 2012

Revista Educação Especial | v. 26 | n. 45, | p. 31-44| jan./abr. 2013

Santa Maria

Disponível em: <http://www.ufsm.br/revistaeducacaoespecial> 